\title{
مرض العوز المناعي المكتسب وأثره \\ على تولية الوظليفة العامة والعزل عنها \\ محاولية لاعادة هندسة ضوابط الوظيفة العامة
}

\section{AIDS and its impact on the assumption and removal of public service Contribute to the re-engineering conditions of public service}

أ.م.د.وليد مرزة المخزومي

كلية القانون , جامعة بغداد

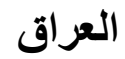

Assistant professor Dr.

Walleed Mirza Almakzomy

Collage of Law

University of Baghdad.

Dr.waleed@colaw.uobaghdad.edu.iq 


\title{
الملخص
}

مثل البحث مساهمة في أعادة هندسة شروط تولية الوظيفة العامة والعزل منها بسب المرض

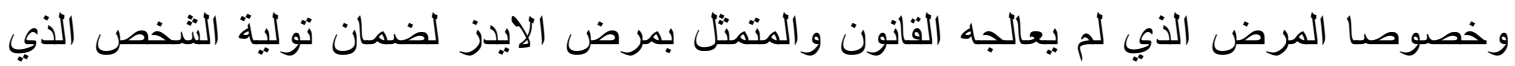
يتمتع بأفضل قدر من الصحة البدنية و النفسية.

الكلمات المفتاحية : الوظيفة العامة، الصحة البدنية و النفسية، مرض (الايدز)

\begin{abstract}
The research represents a contribution to the re-engineering of the conditions of the assignment of the public service and isolation of them due to illness, especially the disease, which was not treated by the law of AIDS to ensure the transfer of the person who enjoys the best physical and psychological health.
\end{abstract}

Key words: public service, physical and psychological health, AIDS 


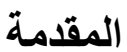

\section{Introduction}

لعل من البداهة القول بخطورة مرض العوز المناعي المكتسب ومقدار الضرر الذي يسببه للمصابين به وللاولة التي ينتمون اليها بسبب تكاليف علاجه الباهضة فضلا عن الاثار الاجتماعية والاقتصادية

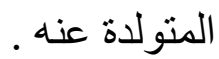

العوز المناعي المكتسب علة او مرض يلحق الانسان عند اهل العلم على نحو يفضي الى تدمير الجهاز المناعي لجسمه وجعله فريسة سهلة لسائر الامر اض حتى يودي به تدريجا الى الموت وهو مرض لا يوصف به الثخص الا اذا تو افرات فيه الثروط الاتية: -

الثرط الاول :المعانة من إنتان انتهازي أو أكثر أو الاصابة بسرطان الجلد المسمى بمرض

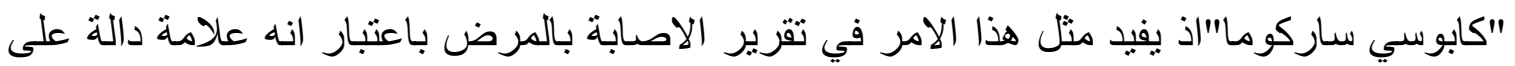
بدء انهيار جهاز المناعة عند المريض المصاب به.

الثرط الثاني : أن يكون عمر الثخص المستهدف من المرض أقل من · ج عاماً ، مع سبق تمتعه بصحة جيدة قبل بدء ظهور عوارض الاعتلال لديه.

الثرط الثالث :أن لا يعاني الثخص المشتبه باصابته من أي من الأمور الطبيعية المتعارف عليها

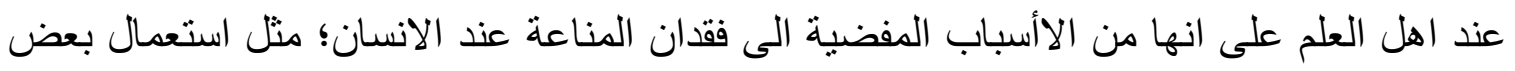

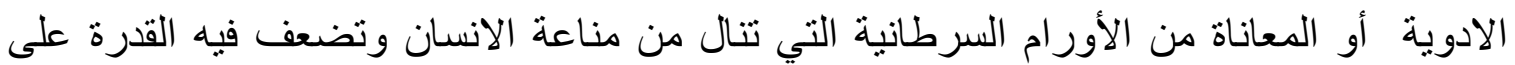

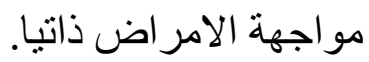

الشرط الرابع : القدرة عزل الفيروس المسبب لمرض العوز المناعي المكتسب (HTLV 111) من المريض فعليا، أو على أقل الفروض كثف الأجسام المضادة الخاصة بهذا الفيروس في دم

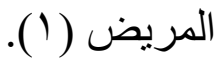

يفيد المرض كما يرى اهل العلم عند الاصابة به الى الاتلاف التدريجي لجهاز المناعة عند الانسان المصاب به حتى يجعل منه هدفا سهلا المنال لسائر الامرض ليقوده بعدها نحو الموت لا محالة وهو 
قبل ذلك يترك في المريض به مجمو عة من العلل والامر اض التي كان سيدفعها عن نفسه لو لا ما

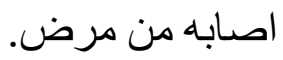

الوظيفة او الخدمة العامة في النظام القانوني العر اقي مثلما هي في غيره من النظم القانونية المقارنة تعد تكليفا وطنيا وخدمة اجتماعية يستهدف الثخص الطبيعي الذي تعهد له مهماتها تحقيق المصلحة العامة وخدمة المو اطنين وهي في حققتها تتجسد في مجموعة متكاملة من الحقوق و الواجبات التي اوجبها المشرع على الموظف والتي قضى باستحقاقه لها نظير قيامه بما الزمه من واجبات(؟).

و الانخر اط في سلك الوظيفة العامة حق لكل مواطن (ّ) متما تو افرت فيه شروطها(ع) وحاز القدرة على اداء مهماتها على خير وجه وحقه هذا مكفول بطائفة من المبادیى الدستورية التي جرت سنة الاغلب الاعم من المشرعين على وضعها نصا فيما يشرعون من دساتير ولعل من اهمها مبدأين

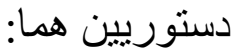
المبدأ الاول : مبدا المساو اة في تولي الوظائف العامة(o) سواء نص عليه المشرع الدستوري صر احة

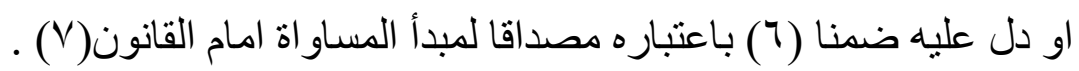
المبدأ الثاني : مبدا مشاركة المو اطنين في ادارة الثؤون العامة التي تتحقق للمواطن بشتى الطرق التي يختطها المشر ع له ومنها تولي الوظائف العامة والاسهام من خلالها في الثؤون العامة تخطيطا

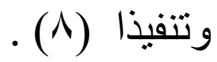

وحاصل القول بجماع هاذين المبدأين هو ان لكل مواطن من ذكر او انثى حق التقدم الى الوظائف العامة متما حاز شر ائط تقلدها من دون تمبيز .

ولكن هل للمريض بمرض العوز المناعي المكتسب مثل هذا الحق ابتدأًُْ وما الحكم ان اصيب به بعد دخوله في سلكها وتوليه اعمالها وتمتعه بحقوقها زمنا طال ام قصر فهل يباح له الاستمر ار فيها

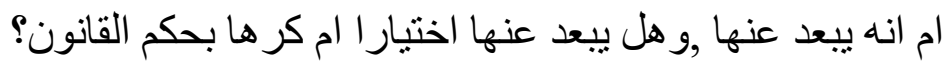

لعلنا لا نجانب الصو اب بالقول ان اجابة مثل هذا التساؤل تكون على شقين يجسد كل شق منهما حكما مختلفا عن الاخر تبعا للمسألة القانونية التي يثيرها هذا المرض والذي يأتي الحكم جوابا على

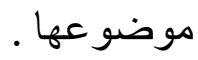


الهمية البحث Importance of Research: تكمن اهمية البحث في هذا الموضوع في وجهين : L

الوجه الاول:وجه نظري يتمثل بعدم وجود دراسة تناولت هذا الموضوع بالبحث و التحليل لما يمكن ان ينجم عنه من مشكلات قانونية.

الوجه الثاني :وجه عملي يتجسد في انه محاولة متواضعة لرسم خارطة طريق امام المشرع

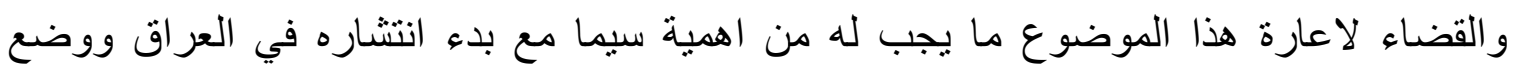
المعالجات التشريعة و القضائية المناسبة لما قد ينجم عنه من مشكلات.

مشكلة البحث Research problem : تتجسد مشكلة البحث في غموض الوضع القانوني في القانون العراقي للموظف الذي يصاب بمرض العوز المناعي المكتسب بما يحويه من حقوق وو اجبات قانو نية سو اء اكان هذا الثخص مصابا بهذا المرض او حاملا له و على مستويين هما : المستوى الاول : حق المريض او الحامل للمرض في تولي الوظيفة العامة بسائر درجاتها الاعتيادية

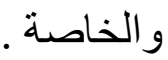

المستوى الثاني :حق الادارة في اقصاء المريض عن الوظيفة او ابعاده عنها باعتبار انه لم يعد قادرا

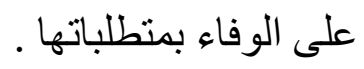
فرضية البحث Search Hypothesis : يسعى البحث الى اثبات فرضيتين هما: الفرضية الاولى:ان مرض العوز المناعي المكتسب يثكل مانعا من انخر اط الثخص المصاب به في

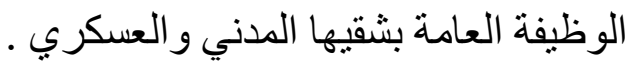

الفرضية الثانية : ان مرض العوز المناعي المكتسب يشكل سببا لاقصائه منها ان اصيب بعد انخر اطه فيها.

خطة البحث Research Outline: في ضوء مشكلة البحث وما تم وضعه من فرضيات وما حصلنا عليه من مصادر سنبحث الموضوع على وفق الخطة الاتية: المبحث الاول: مرض العوز المناعي المكتسب وحق تولي الوظيفة العامة . 
المبحث الثاني : مرض العوز المناعي المكتسب وحق العزل من الوظيفة العامة

\section{المبحث الاول}

\section{مرض العوز المناعي المكتسب وحق تولي الوظيفة العامة}

\section{AIDS and the right to assume public service}

عقد هذا المبحث محاولة لتقديم أجابة عن المسألة المتمثلة في هل للمريض بمرض العوز المناعي

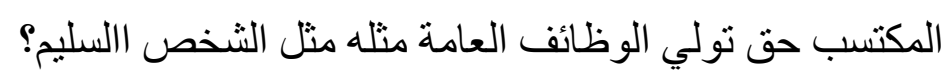

ثبت لنا بالاستقر اءو التحليل النصي لمختلف تشريعات الوظيفة العامة في العراق ان الحكم في هذه المسألة يتجسد في أعتبار المرض هذا مانع من موانع التعيين في الوظيفة العامة يحول بين المواطن

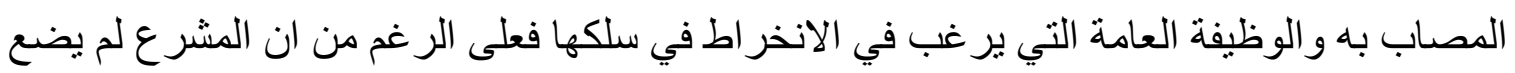
لهذا المرض حكما معينا ولا تناوله بالبيان مع شيو عه وشدة خطره وضرره وحاجة المجتمع لمعرفة

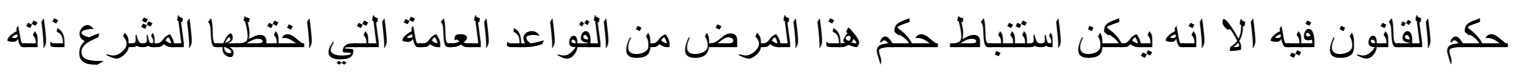
للمرض عموما ومدى جواز تمتع المصاب به بحق تولي الوظائف العامة وذللك بالقول الاتي :

يشكل مرض العوز المناعي المكتسب مانعا من موانع تولي الثخص الوظيفة العامة ابتداءً ابي انه

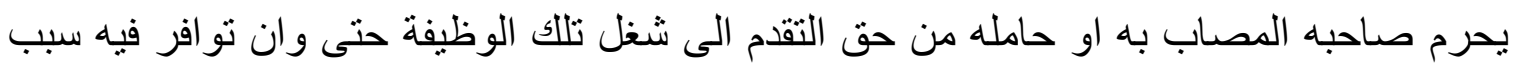
تقلدها ,إعمالا للقاعدة القانونية القاضية بتقديم حكم المانع على حكم السبب (إذا تعارض المانع و المقتضي يقدم المانع ). (9)

فالمرض و الحال هذه مانع من التولي و التعيين إذ يشترط في المتقدم لثنل الوظائف العامة ان يكون صالحا لها و صلاحه لها لا يكون الا اذا كان حائز ا على القدرة البدنية و العقلية و النفسية التي تمكنه من النهوض بأعباء واجباتها ,فما من وظيفة منها الا وتستلزم في صاحبها قدر ا معينا من تلك القدرة وبالنحو الذي ينو افق مع أداء منطلباتها المهنية(·). 
ودليل هذا الحكم يتجلى في العديد من الثواهد التشريعية المستوجبة لوجوب القدرة كشرط للتعيين و التي نكتفي منها بالثو اهد الاتية :

الثـاهد الاول : منطوق نص الفقرة الثالثة من المادة السابعة من قانون الخدمة المدنية ذب الرقم ع؟

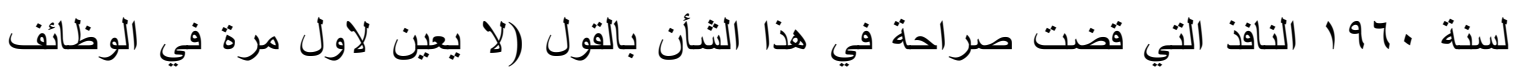
الحكومية الا من كان:. ناجحا في الفحص الطبي وسالما من الامراض المعدية ومن الامراض و العاهات الجسمية والعقلية التي تمنعه من القيام بالوظيفة المعين لها بموجب قرار من السلطات الهرديات الطبية المختصة وفقا لنظام خاص).

فظاهر من عبارة هذا النص ان المشرع قد قضى بحرمة تعيين المصاب بالامراض المعدية و الجسمية و العقلية(') التي تمنعه من النهوض باعباء الوظيفة المتقدم الشغلها صر احة بدليل تصديره النص بحرف (لا) التي تسبق الفعل المضار ع و التي تفيد النهي عن التعيين على وجه الجزم .

وحكمة النهي هنا عن التعيين انما تأتي باعتبار ان تلك الامر اض الموصوفة في النص تحول بين المريض بها وبين اداء الو اجبات الوظيفية التي من اجل ادائها اريد تعيينه خدمة للصالح العام, و القول بخلاف ذللك يفوت القصد من وراء نظام الوظيفة العامة ويودي بمصالح الناس الى الضياع ان نم عهد الوظيفة العامة للثخص الطبيعي العاجز عن اداء مقتضياتها والوفاء بمتطلبات اعمالها في قضاء مصالح الناس و اشباع حاجاتهم.

الثاهد الثاني : منطوق نص الفقرة الثالثة من المادة الثامنة من قانون الخدمة البحرية المدنية ذي

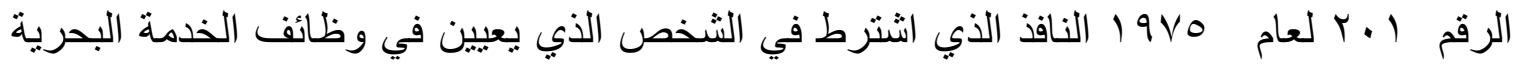
المدنية القدرة البدنية والسلامة من الامر اض والعاهات الجسدية والعقلية بدليل قول المشرع فيها (يشترط فيمن يعين لأول مرة في الوظائف و المهن المبينة في الجدول الملحقة بهذا القانون، أن يكون: rـ ناجحاً في الفحص الطبي، وسالماً من الأمر اض المعدية، ومن الأمراض ولاض والعاهات الجسمية و العقلية التي تمنعه من القيام بالوظيفة المعين لها بموجب قرار من السلطة الطبية المختصة.).

الثاهد الثالث: منطوق نص الفقرة (د) من المادة ؟ /ثانيا من قانون الخدمة الخارجية ذب الرقم ـ؛

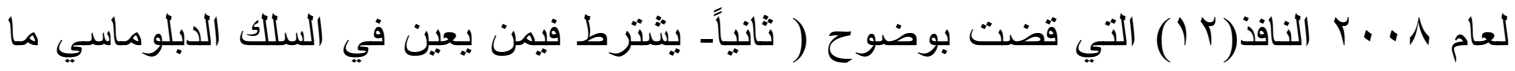


يأتي:د - سالم من الامر اض المعدية والعاهات العقلية التي تمنعه من القيام بوظيفته المعين فيها بموجب قرار من اللجنة الطبية المختصة.).

الثـاهد الرابع : منطوق نص الفقرة سادسا من المادة الخامسة من قانون الخدمة والتقاعد لقوى الامن

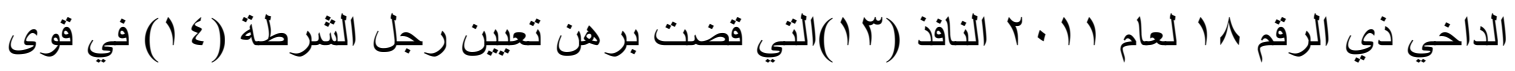
الامن الداخلي بحيازته لثروط اللياقة البدنية والسلامة الصحية التي تثبت قدرته البدنية والعقلية و النفسية على اداء الواجبات الوظيفية المعهودة لرجل الثرط بدليل صيغة النص التي جاء على وفق صيغة الجملة الثرطية المصدرة بالفعل المضارع الذي يفيد الامر للمخاطب به وهو الادارة المختصة بالتعيين بقو لها (يشترط فيمن يعين ضابطاً ان يكون: سادساً - مستوفياً شروط اللياقة البدنية و السلامة الصحية.),وبالمثل منطوق نص الفقرة رابعا من المادة ـ ب من القانون ذاته التي قضت بأنه (يعين المنتسب وفقا للثروط الاتية-: رابعا- ان يكون مستوفيا شروط اللياقة البدنية والسلامة

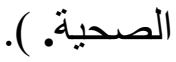

الثاهد الخامس : منطوق نصوص نظام اللياقة الصحية ذي الرقم 0 لعام ب991 المعدل والتي اثترطت فيمن برغب من المو اطنين من الرجال والنساء في تولي الوظائف العامة تعيينا ان يكون حائزا للياقة الصحية و اللياقة الصحية في مذهب هذا القانون (0 (1).هي القابلية البدنية والعقلية و النفسية التي يجب تو افرها في الثخص ليكون لائقا للخدمة في دوائر الدولة والقطاع العام وجاء

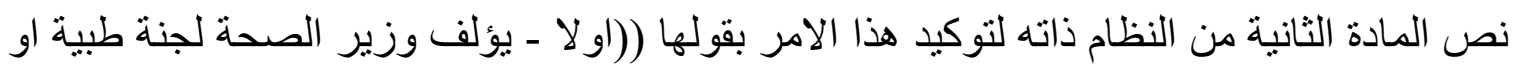
اكثر في مدينة بغداد وفي مركز كل محافظة لفحص المرشحين للخدمة في دوائر الدولة والقطاع الاشتر اكي باستثناء العاملين في الطيران المدني .)).

ومعيار صلاح الثخص المتقدم للتعيين في الوظائف العامة معيار يلجأ فيه الى اهل الخبرة من الاطباء المثلين في اللجنة الصحية التي يعينها الوزير لهذا الثان ويكون قرار ها الفيصل في صلاح الثخص او عدم صلاحه لتولي الوظيفة العامة.

و هي لجنة طبية تتشكل من رئيس و عضوين تتولى فحص المتقدم للتعين (7 (1) تصدر ها قرارها المسبب على وفق الضو ابط الاتية(V ) ( V ): 
الضابط الاول: ان يكون الثخص المتقدم للتعيين في الوظيفة العامة ذا لياقة بدنية تؤهله للعمل المناط

الضابط الثاني: ان لا يكون هذا الثخص مصابا باحد الامر اض المزمنة او المستعصية او النفسية او العقلية او العصيبة التي تؤثر على عمله.

الضابط الثالث: ان يكون الثخص في نطقه طبيعيا ومفهوما وسمعه طبيعيا وتتبت درجة السمع في حالة وجود شك من الطبيب المختص.

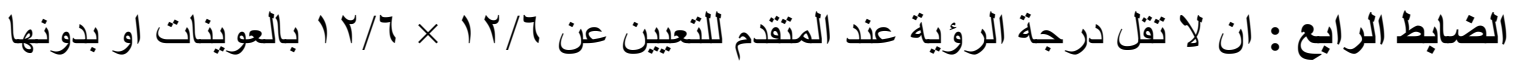
او ما يعادلها حسابيا على ان يكون سالما من عمى الالوان الكلي والعشو الليلي وغير مصاب

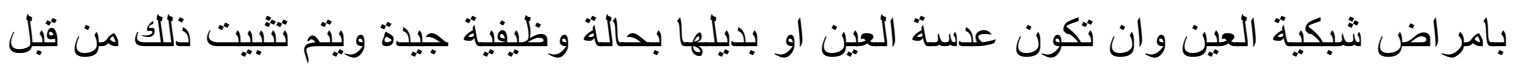
الطبيب المختصص بطب العيون .

الضابط الخامس: ان لا يكون المتقدم للتعبين مصابا بالرارا (نستاكوس) او الحول الثابت الذي يؤثر على قدرته على القيام بو اجبات الوظيفة المر اد عهدها اليه.

وقرار اللجنة هذا بتقرير صلاح الثخص للوظيفة او عدم صلاحه لمتطلباتها يكون قابلا للطعن خلال • ب يوما من تاريخ التبلغ به رامام لجنة استئنافية يشكلها الوزير للنظر في قرار لجنة الفحص وهي تتالف من رئيس واربعة اعضاء من الاطباء المختصين هدفها التحقق من صحة قرار الفحص من عدمه وقرارها هذا يكون باتا قاطعا لا محل فيه للمر اجعة والتعقيب سواء اقر للشخص بالصلاح لتولي الوظيفة او اقر عدم صلاحه لتوليها(^). المبحث الثاني

مرض العوز المناعي المكتسب وحق العزل من الوظيفة العامة

\section{AIDS and the right to be separated from public service}

وضع هذا المبحث الفقهي محاولة لاجابة مسألة قو امها ما الحكم ان اصيب الموظف بالمرض بعد دخوله في سلك الوظيفة العامة وتوليه اعمالها وتمتعه بحقوقها زمنا طال ام قصر فهل يباح له له 
الاستمر ار فيها ام انه يبعد عنها ووهل يبعد عنها اختيار ا بحض ارادته ام بار ادة الادارة التي يعمل فيها ولمصلحتها ام يبعد كر ها بحكم القانون وقوته؟

تفيد القر اءة المعقة لنصوص التشريعات الحاكمة للوظيفة العامة في العر اق ان الحكم في هذه المسألة هو أن هذا المرض يشكل سببا قانونيا لاقصاء الموظف من الوظيفة العامة التي سبق ان اسندت اليه قانونا مسقطا حقه في الاستمر ار فيها بأعتبار بعد انه يفضي ال زو ال قدرته على العمل و التي تشكل

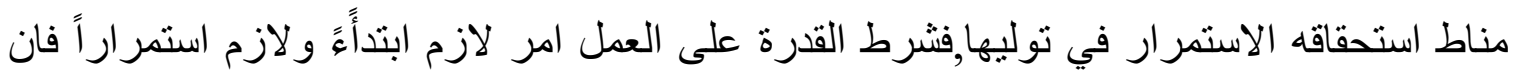
زالت تللك القدرة عن الموظف لاي سبب كان زال معه أمكان بقاء هذا الموظف في تلك الوظيفة.

وحكم الاقصاء هنا حكم حتمي يترتب على المرض بحكم القانون رباعتبار ان المشرع اوجب على الى الماء الادارة انهاء خدمة الموظف ان اصيب بمرض اقعده عن العمل وإحالته على التقاعد لعدم صلاحه للاستمر ار في اداء الخدمة العامة و على نحو ليس لها معه باعتبار ها المخاطبة بهذا النص الا احالة الموظف الى التقاعد بعد ثبوت اصابته بالمرض بصرف النظر عما له من خدمة وظيفية وقرار ها في هذا الثان لا يعدو ان يكون الا تدبير اكاثنفا لا منشئ لامر الاحالة باعتبار انها تقع بقوة القانون

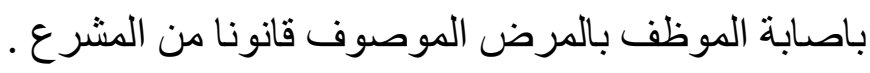
و هو حكم قانوني يمكن الاستدلال عليه من خلال استظهار الادلة القانونية الاتي ذكرها في هذا البيان

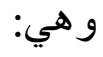
الدليل الاول : نص الفقرة ثانيا من المادة العاثرة من الفصل الخامس الموسوم بالاحالة على التقاعد من قانون التقاعد الموحد ذي الرقم 9 لسنة ؟ ا ـ النافذ(9.) التي قضت بالحكم الاتي : (تتحتم إحالة الموظف إلى التقاعد في إحدى الحالتين الآتيتين:ثانياً ـ إذا قررت اللجنة الطبية الرسمية المختصة عدم صلاحيته للخدمة. ). (ل).

ظاهر من قراءة هذا النص ان منطوقه الصريح قضى باقصاء كل شخص عما اسند اليه من وظيفة

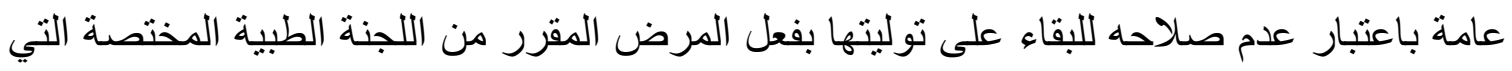
اوكل لها المشرع مهمة تقرير الاقصاء والفصل في استمرار المريض في العمل باعتبار انه

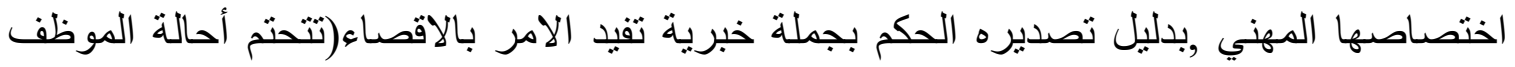


الدليل الثاني : نص المادة ـ 10 ـ من قانون التقاعد رقم 9 لسنة ـ ا ـ النافذ في فقرتها الاولى بقولها( اولاً. إذا اصيب الموظف في أثناء الخدمة بمرض يستوجب العلاج لمدة طويلة أو كان من الأمر اض المستعصية وقررت اللجنة الطبية عدم صلاحيته للعمل بصورة نهائية فيحال إلى التقاعد

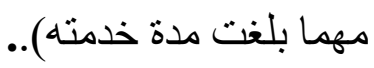

و هو دليل يفيد الحكم السابق ذاته اذ رتب على الاصابة بالمرض المستعصي او المنطلب للعلاج طويل الامد اقصاء الموظف عن الوظيفة تقاعدا شريطة ان يترتب على مرضه ثبوت عدم صلاحيته للبقاء في الوظيفة على وفق قرار صادر عن لجنة طبية مختصة من اهل العلم

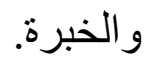

الاليل الثالث : نص المادة الثانية من قانون العجز الصحي ذي الرقم / 1 لسنة 1999 النافذ(·) التي قضت صر احة بالاحكام الاتية:

(او لأ:إذا أصيب الموظف بمرض يستوجب علاجه مدة طويلة أو كان من الأمر اض المستعصية أو الخبيثة المحدة من وزارة الصحة، فيمنح إجازة مرضية خاصة براتب تام مدة أقصاها ب ثلاث سنو ات بقر ار من اللجنة الطبية.

ثانيا:عند انتهاء الإجازة المرضية الخاصة المنصوص عليها في البند او لأ من هذه المادة، يعاد فحص

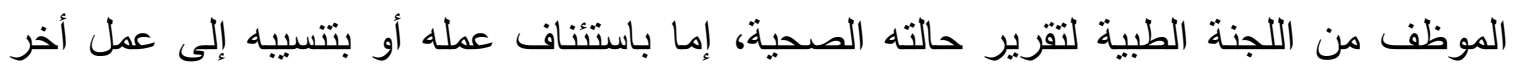
يتناسب مع حالته الصحية وإما بتقرير عدم صلاحيته للعمل نهائيا فيحال عندئذ على التقاعد مهما

و الحكم المستفاد من قراءة عبارة منطوق هذا الدليل كذلك هو اقصاء الموظف المريض بمرض

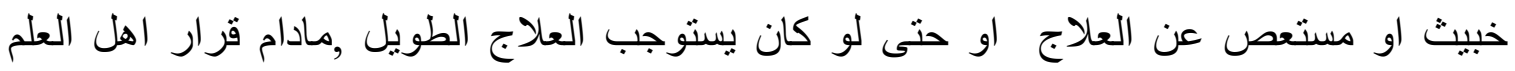
الممثلين في اللجنة الطبية الرسمية المختصة ,قد قضى ان الموظف المريض و الحال هذه لا يجوز له له

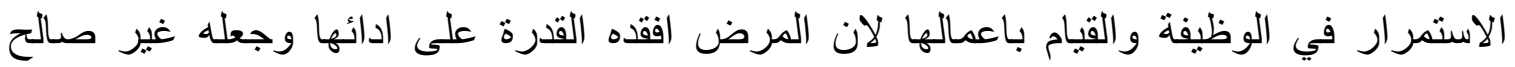


و هو حكم تدلل عليه الصيغة المستعطلة في النصين السابقيين والمصدرة بأداة الثرط (إذا) اصاب الموظف المرض وقررت اللجنة عدم صلاحيته للعمل بصورة نهائية فانه يقصى عن الوظيفة تقاعدا

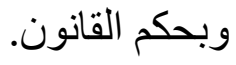

الدليل الرابع : نص منطوق الفقرة سادسا من المادة بr من قانون الخدمة والتقاعد لقوى الامن

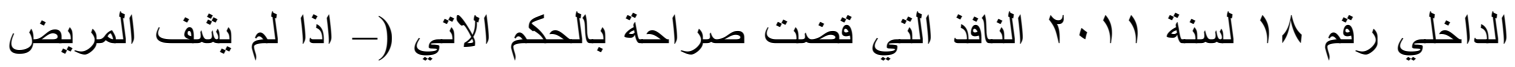

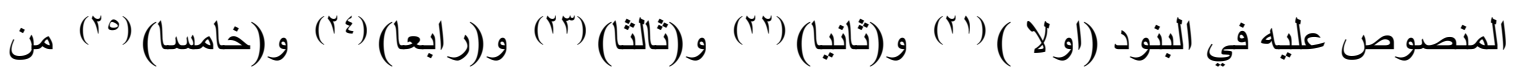
هذه المادة بعد استفاد اجازاته الاعتيادية والمرضية المنصوص عليها في هذا القانون يحال الى لى لئ التقاعد بناء على تقرير طبي صادر عن اللجنة الطبية وتحتسب الخدمة (10) خمس عشرة سنة لاغر اض التقاعد اذا كانت خدمنه تقل عن ذلك. . ).

وظاهر هنا ان المشرع قد رتب حكم الاقصاء عن الوظيفة على رجل الثرطة الذي يصاب بالمرض و لا يشفى منه ويستنفل اجاز اته جميعا الاعتيادية والمرضية على نحو لم يعد لبقائه في الوظيفة من

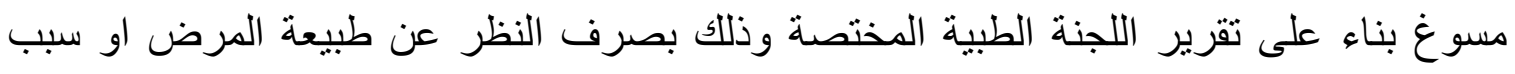
الاصابة اثناء الخدمة ام كان خرجها , بسببها ام بغيره فكلها احوال تستوي عند المشرع في الحكم بدليل قوله (يحال الى التقاعد...) والمرض ورد هنا على وجه العموم بما بعني انه يشمل العوز المناعي المكتسب كما يشمل غيره.

الدليل الخامس : مفهوم نص الفقرة الثالثة من المادة السابعة من قانون الخدمة المدنية ذب الرقم عب لسنة . 197 النافذ التي قضت صر احة في هذا الثأن بالقول (لا يعين لاول مرة في الوظائف

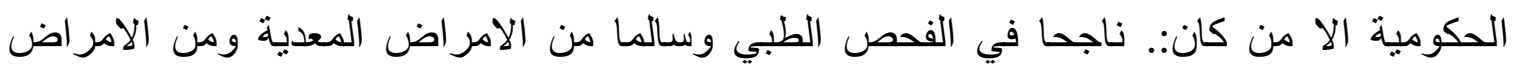
و العاهات الجسمية والعقلية التي تمنعه من القيام بالوظيفة المعين لها بموجب قرار من السلطات الطبية المختصة وفقا لنظام خاص).

فهذا المفهوم يفيد القول بوجوب اقصاء الموظف المريض عن الوظيفة العامة المعهودة اليه ان افضى المرض الى اعدام قدرته على الوفاء بمنطلباتها واتمام اعمالها كما افاد بالمثل منطوق النص سابقا في لهي تحريم تعيينه ونهي الادارة عن القيام به بسبب ذللك المرض المقعد له عن العمل,وعلى هذاه كما كما كان المرض مانعا من موانع التعيين فأنه بالمثل سبب للاقصاء عنه لاتحادهما في العلة الموجبة للنهي 
و الاقصاء المتمثلة في عدم حيازة الثخص المريض للقدرة البدنية والعقلية والنفسية التي تتكل مناط التعيين و اساسه وشرطا رئيسا من شروط استحقاقه القانوني.

هذا وسائر الاوصاف التي خلعها المشرع في النصوص السابقة على الامر اض المفضية الى الاقصاء

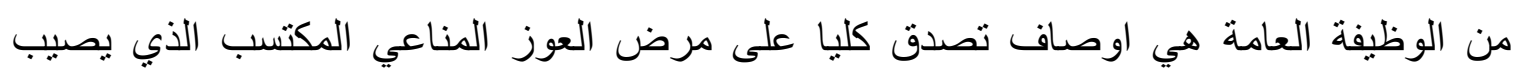
الموظف في حياته الوظيفية كما تم اثباته بر اي اهل العلم و الخبرة.

و الاقصاء الو اقع على الموظف المريض انما يكون بالاحالة على التقاعد الناجز بحكم القانون شريطة ان يترتب هذا الحكم بناء على تقرير يصدر عن اللجنة الطبية المختصة في وزارة الصحة و التي عهد

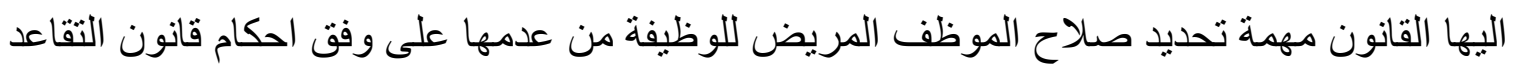
الموحد ذي الرقم 9 لسنة ـ ا ـ ب المعدل .

وحسنا فعل المشرع في هذا الثنان فانهاء حياة الموظف المريض بالعوز المناعي المكتسب بالتقاعد,نتيجة اصابته بهذا المرض حل يتفق مع واجب الدولة في حماية مواظفيها وتوفير سبل العيش الكريم لهم عند المرض سيما وانه كان يعمل في خدمتها ويؤدي اعماله لصالحها, ولكن ماذا لو كانت خدمة الموظف المريض اقل من الحد الادنى الواجب توفره للاحالة الى التقاعد والبالغة 10 سنة ميلادية او كان عمره عند الاصابة بالمرض اقل من العمر الذي حدده المشرع لصرف الراتب لبره

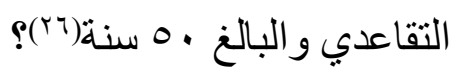

عالج المشرع العراقي هذا الامر فاخرج الموظف المريض بالعوز المناعي المكتسب من الخضوع الى حكم هاذين الثرطين فقضى باحالته الى التقاعد بأن رفع مقدار خدمته الى الحد الادنى المطلوب قانونا للاحالة على التقاعد من ناحية وقضى بالمثل بصرف ر اتبه التقاعدي مهما كان عمره من ناحية ثانية رعاية لوضعه الصحي السيء.

و هو حكم يستفاد صر احة من منطوق نص المادة ـ 10 بقوله (اولاً إذا اصيب الموظف في أثناء الخدمة بمرض يستوجب العلاج لمدة طويلة أو كان من الأمر اض المستعصية وقررت اللجنة الطبية عدم صلاحيته للعمل بصورة نهائية فيحال إلى التقاعد مهما بلغت مدة خدمته. 
ثانياً تبلغ الخدمة التقاعدية للموظف المشمول بأحكام البند (اولاً) من هذه المادة إلى (10) خمس

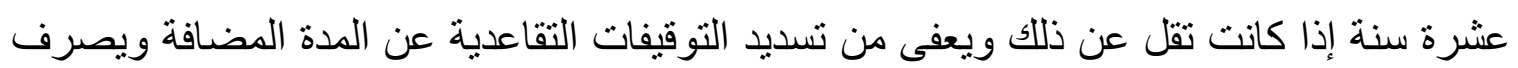
راتبه التقاعدي مهما كان عمره).

و على هذا يكون مناط استحقاق المواطن لحكم تولي الوظائف العامة هو صلاحه وصلاحه رهين بامتلاكه القدرة البدنية والعقلية السليمة التي تمكنه من الوفاء ما تضعه على عاتقه تللك التولية من واجبات قانونية وصلاحه رهين بعدم اصابته بمرض من الامر اض التي وصفتها النصوص القانونية و اعتبرتها مانعا من تولي الوظائف العامة لا سيما المعدية و المقعدة عن العمل او الخبيثة والمستعصية عن العلاج,وعلى الرغم من عدم وجود اشارة لمرض العوز المناعي المكتسب في النصوص

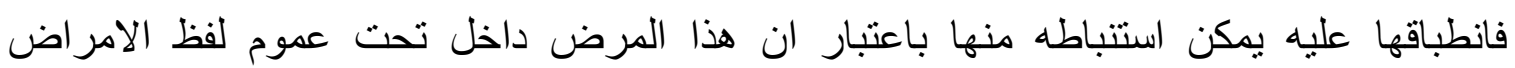
الموصوفة في النص فهو : إنهن

1 ـمن الامر اض المعدية في عرف اهل العلم والخبرة من المختصين إذ ينتقل من الثخص المريض

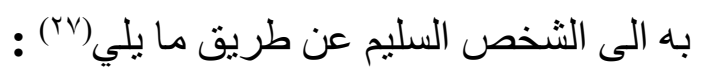
ـالجماع غير الامن الثرعي منه وغير الثرعي فهما في الحكم سواء إذ يشكل السبب الاول للعدوى

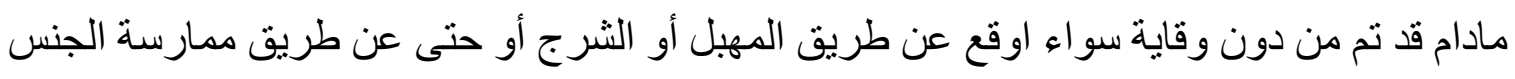

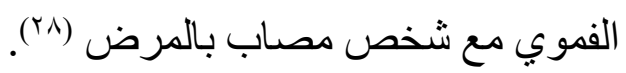

ـنقل الدم الملوث بفايروس المرض من جسد المريض الى جسد السليم بصرف النظر عن آلية النقل

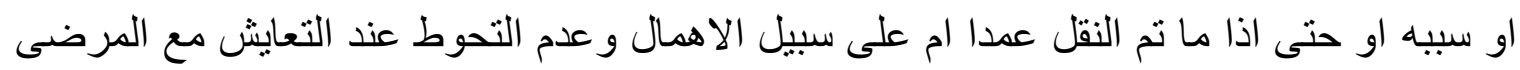
المصابين به. (ra)

-تبادل استعمال الإبر أو المحاقن وآلالات الوشم الملوثة أو أية أدوات حادة ملوثة بالسوائل لحاوية على فايروس هذا المرض. ـالانتقال من الأم المريضة إلى الجنين الذي تحمله أثناء الحمل والولادة و إلى الرضيع أثناء الرضاعة (•"). 
الوصف الثاني : من الامراض الجسدية التي تصيب جسد الانسان اصلا وتنال تدريجيا من اجزته

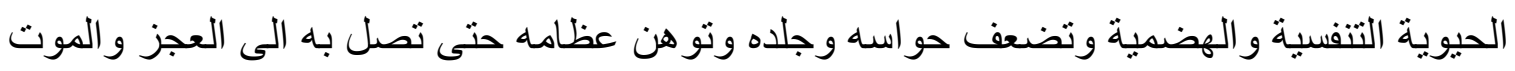
في نهاية المطاف في مدة زمنية قد تقصر وقد تطول من مريض الى اخركما يفيد اهل العلم في هذا

إذ يمرّ المريض به بأطو ار صحية مختلفة تتدرج من الضعف الى الثندة حتى يصل الى النهاية

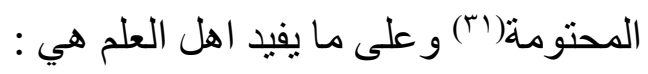

الطور الأول : وهو اول طور يمر به المريض واقلها اثرا على صحته ويندر ان تظهر عليه

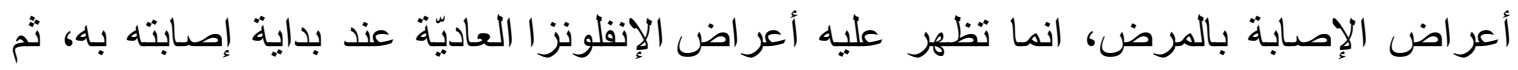
تختفي هذه الأعر اض بعد أسبو عين على الأكثر، فضلا عن انه يصاب بانتفاخات في الغدد الليمفاويّة، وقد يصاب بطفح جلدي.

الطور الثاني :وهو الطور الثاني الذي يتميز بانه غير محدد باجل زمني معين لاختلافه من شخص

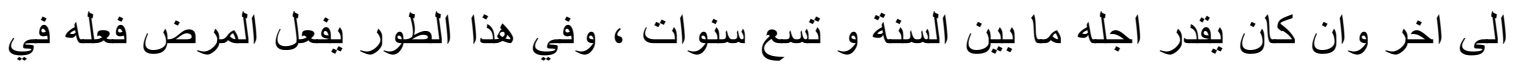
المريض ويتمكّن من جسمه ويدمّر مناعته الجسيّة قبل الامراض بشكل كبير، سيما اصابته بالإسهال الثّديد، و الفقدان السريع للوزن، و إرتفاع في درجة حر ارة الجس، وصعوبة التنفس وضيقه

الطور الثالث :وهو الطور الاخير الذي يقود المريض الى حتفه اذ تبرز عليه اعر اض المرض باجلى صورها واثد ها ضررا به، فيصبح أكثر عرضة للإصابة بالسرّطانات المختلفة، وإلالتهابات الرئويّة الحادّة، فضلا وزيادة عن امر اض الإسهال المزمن، والصيّاع الدائمهو الفقدان الكبير للوزن، و إضطر اب الرؤية، واكتساء اللسان بالنقاط البيضاء الدائمة ووظهور الجروح في جوف الفم، كما ويعاني المريض من القشعريرة الدائمة أو الحمى الدائمة وكذللك من التعرّق اللّيلي الزائد.

الوصف الثالث :من الامر اض العقلية باعتبار انها تصيب العقل فتودي به سيما في الطور الاخير

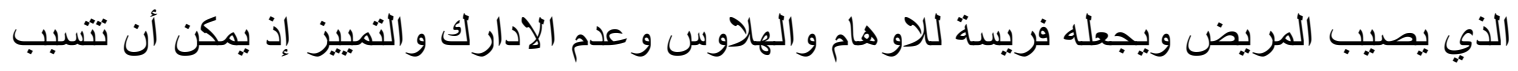
إصابة خلايا الجهاز المركزي العصبي بفايروس HIV المسبب للإيدز في الإصابة بمرض التهاب السحايا غير الصديدي الحاد ومرض التهاب الدماغشبه الحاد ومرض اعتلال الحبل الثوكي 
الحويصلي إلى جانب مرض اعنلال الأعصاب الطرفية, الأمر الذي يمكن أن يترتب عليه في وقت لاحق الإصابة بالخرف المركب أو الخرف المصاحب لهذا المرض سيما انه تظهر بعض آثار الضعف أو الخلل العصبي الناتجين عن هذا الفيروس في صورة اضطرابات إدراكية وسلوكية وحركية تظهر بعد مرور سنوات من الإصابة هذا وتتجسد هذه الاثار العصيبة في اختلال القوى

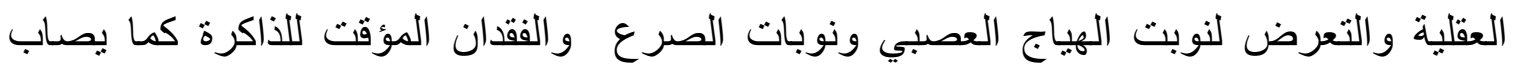
المريض كذلك بكثرة النسيان وضعف الذاكرة وعدم القدرة على التركيز ، كما يقوم بأداء بعض ونص

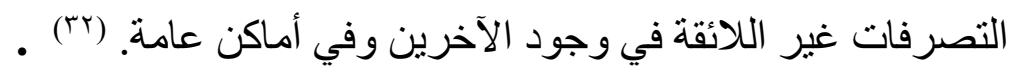

الوصف الرابع : الامراض المقعدة عن العمل حتما باعتبار اعدامه قدرة المريض به الجسدية

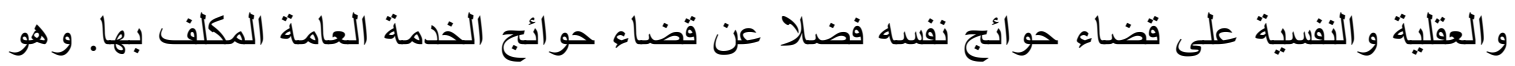
بهذا الوصف علة تمنع المريض من التعيين مادام يعدم قدرة الانسان على قضاء حو ائجه الذاتية كما يعدم قدرته على اداء ما يوكل له من الثؤون العامة سيما وان هذه الثؤون تتطلب قدرة بدنية و عقلية لا تتو افر بقول اهل الطب فيه لاعدام المرض لها او انقاصها الى الحد الذي لا ينتفع به لخدمة الصالح العام.

الوصف الخامس : الامر اض الخبيثة والمستعصية حتى الزمن الحاضر على العلاج مما يجعله سببا رئيسا للاقصاء الموظف المصاب به عن الوظيفة التي يتقلدها, وبمقايسة خطورة هذا المرض الترفي بخطورة الامر اض الخبيثة و المستعيصة التي عدها المشرع سببا لاقصاء الموظف عن الوظيفة يقودنا الى القول انه اولى منها بترتيب حكم الاقصاء على الموظف باعتبار زيادة خطورته على خطورتها وجسامة الضرر الذي يلحقه بالموظف المصاب به اثد مما يلحق هذا الموظف من تللك الامر اض

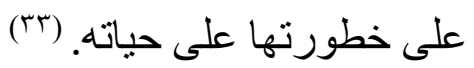




\section{الخاتمة}

\section{Conclusion}

وختام هذه المساهمة و المحاولة البحثية جملة من النتائج و التوصيات التي نعرض أهمها في الكثف

النتيجة الاولى : الاصـابة بمرض العوز المناعي المكتسب او حمل الثخص له يشكل سببا لحرمانه من الكثير من الحقوق التي يقرها القانون المنظم للخدمة العامة المدنية منها و العسكرية في النظام القانوني العر اقي .

النتيجة الثانية:ان مرض العوز المناعي المكتسب هو في المآل مرض موت مما يتوجب معه اجراء احكام مرض الموت على الموظف المصاب به على وفق ما جاء به القانون النافذ في هذا الثأن من احكام و هي الاحكام المبسوطة في القانون المدني العر اقي ذي الرقم اء لعام 901 النافذ.

النتيجة الثالثة:ان مرض العوز المناعي المكتسب يشكل مرضا من الامر اض التي تتال الانسان في جسده ونفسه وهو من الامر اض الخبيثة والمستعصية على العلاج كما افاد اهل العلم والخبرة من الاطباء ومتخصصي الامر اض و علومها .

النتيجة الرابعة : أنطباق وصف الخبث والاستعصاء على العلاج ومرض الموت على مرض فقدان المناعة المكتسبة يجعل من هذا المرض مانعا من انخر اط الثخص المصاب به في الوظيفة العامة بشقيها المدني و العسكري كما يشكل سببا لاقصائه منها وعزله عنها ان اصيب بعد انخر اطه فيها. النتيجة الخامسة : التأكيد على ضرورة الكثف الطبي قبل تولي الوظائف العامة لأهميته، و المصالح الكبيرة المترتبة عليه، وللادارة إلزام المتقدم لتولي الوظائف العامة به، ولها بالمثل اجرائه عليهح ولها حق الإلز ام به بعد توليهم الوظائف العامة حماية للناس و الوظيفة من خطره ـكما افاد اهل العلم

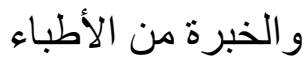


مجلة العلوم القانونية/ كلية القانون - جامعة بغداد / العدد الخاص لبحوث مؤتمر فرع القانون العام المنعقد تحت عنوان"الاصلاح

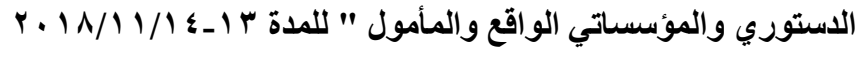

النتيجة السادسة :ان مرض العوز المناعي المكتسب لا يشكل مانعا من موانع المسئؤلية التأديبية ولا

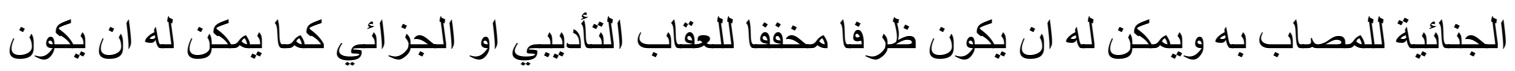
ظرفا مشددا ان ثبت تعدد الموظف المريض به نقله الى سو اهنه

النتيجة السابعة:وجوب أعادة هندسة ضوابط تولية الوظيفة العامة من خلال التوكيد على حيازة المرشح لضابطي القدرة البدنية والنفسية باعتبار هما من عو امل النجاح في الاساسية في تأدية واجبات الوظيفة العامة على أفضل نحو ممكن.

النتيجة الثامنة:وضع تنظيم قانوني واضح لمرض العوز المناعي المكتسب وغيره من الامراض المنقولة جنسيا في مجال الوظيفة العامة لاسيما بالنسبة لحاملي الفايروس المسبب له من حيث تولئ توليته الوظيفة العامة وبشكل يوازن بين اعتبارات المصلحة العامة من جهة ومصلحة المواطن من جهة ثنانية. 


\section{الهوامش}

\section{Margins}

' د. عبدالحميد القضاة ,العوز المناعي المكتسب حصاد الثذوذ ، دار ابن قدامى للطباعة، القاهرة 7191 (م، ص99 ا. ^ انظر في هذا على وجه العموم : د. صلاح احمد جودة ، الرقابة القضائية على التعيين في الوظائف العامة ، رسالة

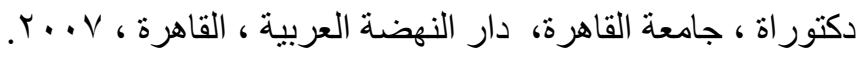

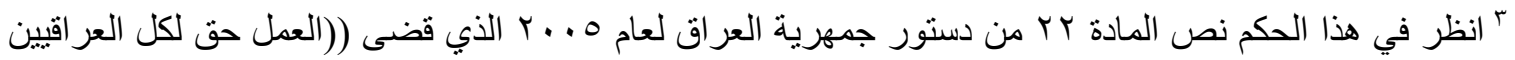
بما يضمن لهم حياة كريمة )). ومثلاه واوضح منه النصوص المقارنة الاتية:

ـنص المادة جr من الدستور البناني لعام \ب9 الاالنافاذ الذي قضى (لكل لبناني الحق في تولي الوظائف العامة ,لا ميزة لاحد على الاخر الا من حيث الاستحقاق والجدارة ,حسب الثروط التي ينص عليها القانون .).

ـنص بالمادة (Yr) من دستور المملكة الاردنية الهاثمية لعام 190 النافذ (على أن لكل أردني حقاً في تولي الوظائف العامة بالثروط المعينة بالقوانين والأنظمة، وأن التعيين للوظائف العامة من دائمة ومؤقتة في الدولة

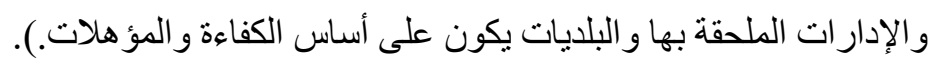

ـنص المادة اه من دستور الجز ائر لعام 997 النافذ على هذا المبدأ بقولها: ( يتساوى جميع الموظفين في تقلد المهام و الوظائف في الدول دون أية شروط، غير الشروط التي يحددها القانون).

ـنص المادة ـ ا من دستور جمهورية مصر العربية لعام ع ا ـ الذي قضى(الوظائف العامة حق للمواطنين على أساس الكفاءة، ودون محابات او وساطة...).

؛ انظر في هذه الثروط نص المادة V من قانون الخدمة المدنية النافذ, و التي قضت بعدم تعين اي شخص ما لم يكن :عراقياً أو متجنساً مضى على تجنيسه مدة لا تقل عن خمس سنوات.واكمل الثامنة عشر من العمر وللممرضة السادسة عشر.,ناجحاً في الفحص الطبي وسالماً من الامراض و العاهات الجسمية والعقلية التي تمنعه من القيام بالوظيفة المعين لها بموجب قرار من السلطات الطبية المختصة وفقاً لنظام خاص., حسن الاخلاق وغير محكوم بجناية غير سياسية او بجنحه تمس الثرف كالسرقة والاختلاس والتزوير والاحتيال.,حائز ا على شهادة دراسية معترف بهاو اخير ا غير مشمول باحكام قانون المسألة و العدالة النافذ.

• انظر للتفصيل في هذا المبدأ : د. محمد إبر اهيم علي ، مبدأ المساواة في تقلد الوظائف العامة ـ دراسة مقارنة،

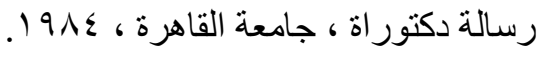


" انظر في ذلك د.مصطفى سالم مصطفى النجفي : المساو اة ودور ها في تولي الوظائف العامة ، اطروحة دكتور اه ،

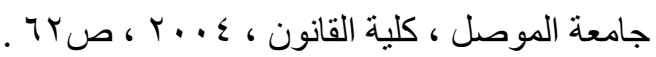

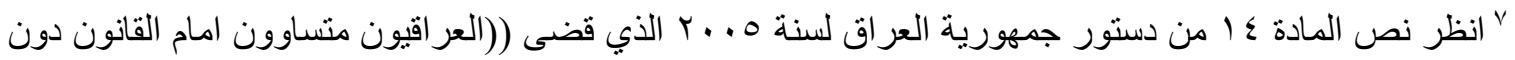

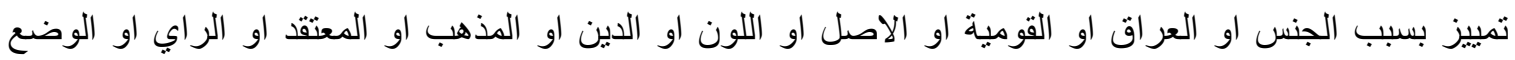

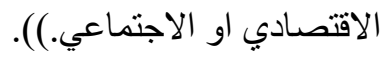

^ انظر نص المادة ·r من دستور جمهورية العراق ذاته الذي قضى ((للموطنين رجالا ونساء حق المشاركةقي الثؤون العامة و التمتع بالحقوق السياسية بما فيها حق التصويت والاتنخاب و الترشيح.)). 9 انظر نص المادة T؟ • r من مجلة الاحكام العدلية.

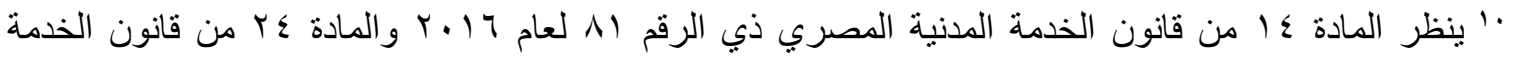

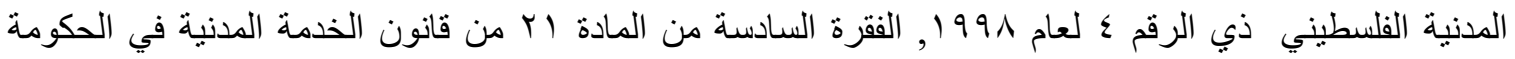

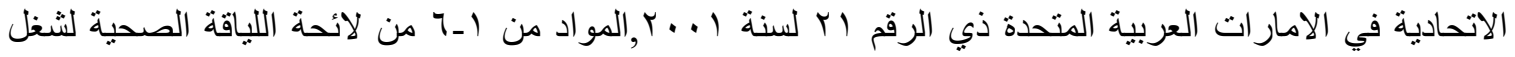
الوظيفة العامة في المملكة العربية السعودية و البند الخامس من المادة الاولى من نظام الخدمة الدننية الكويتي و الفقرة

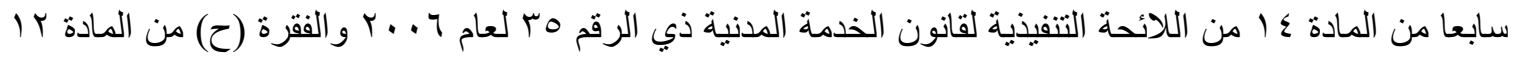

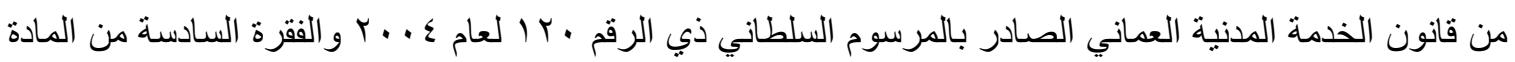

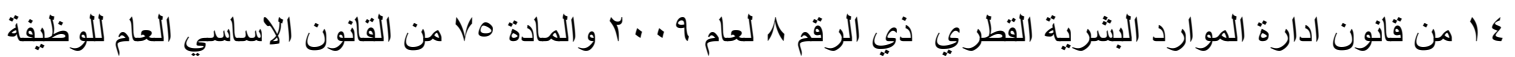

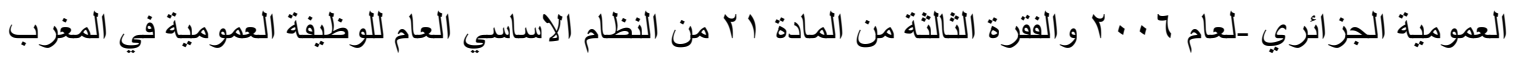

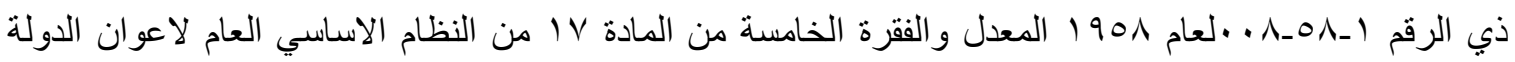

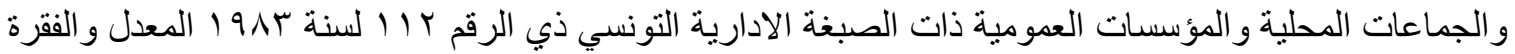

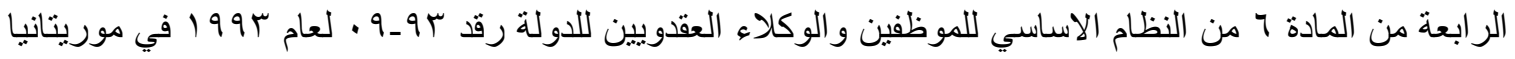

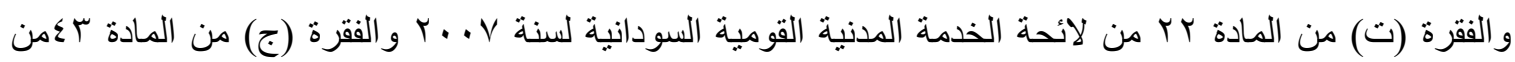

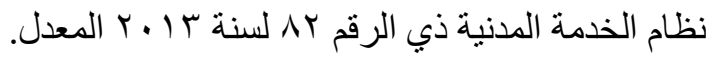
" ويقصد بالمرض : الاعتلال الصحي الذي يمنع الموظف من مز اولة عمله و لا يكون ناثئًا عن إصابة عمل ويحدد

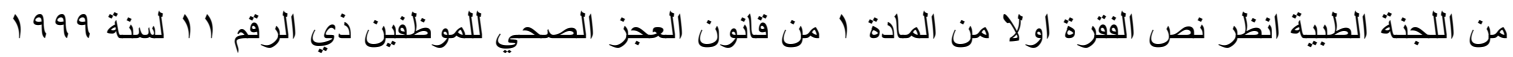

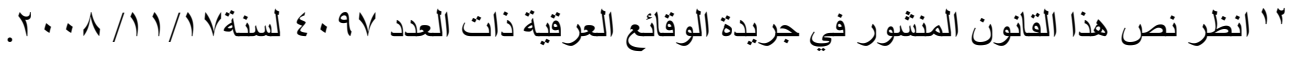

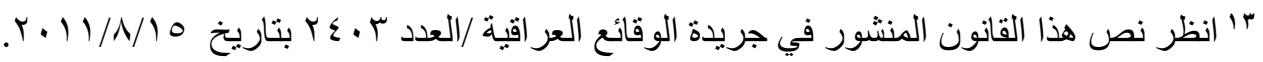


؛' انظر نص الفقرة اسادسا من المادة الاولى من هذا القانون التي حدد مفهوم - رجل الشرطة بأنه : احد أفراد قوى

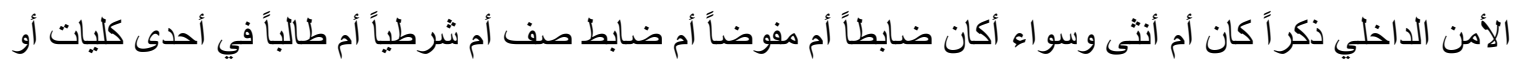
المعاهد أو مدارس قوى الأمن الداخلي وينصرف وصف (الثرطة) الى قوى الامن الداخلي ما لم برد نص خاص في هذا القانون بخلاف ذلك.. ها او هذا هو التعريف الذي نص عليه النظام ذاته في المادة الاولى منه لفظ اللياقة الصحية وهذا هو التشكيل الذي نصت عليه احكام الفقرة ثالثا من المادة الثانية من نظام اللياقة الصحية ذي الرقم ه لسنة ب99 19 النافذ. "14 وهذا هو التشكيل الذي نصت عليه احكام الفقرة ثالثا من المادة الثانية من نظام اللباقة الصحية ذي الرقم ه لسنة r99 199 V' و هذه الضو ابط هي التي جاء بها الجدول الاول الملحق بهذا النظام سالف البيان . ^1 انظر نص المادة r من نظام اللياقة الصحية ذي الرقم ه لعام r99 النافذ التي نصت على (يؤلف الوزير لجنة طبية استئنافية او اكثر من رئيس واربعة اعضاء ير اعى في اختبار هم الاختصاصات الطبية المختلفة ويكون قرارها

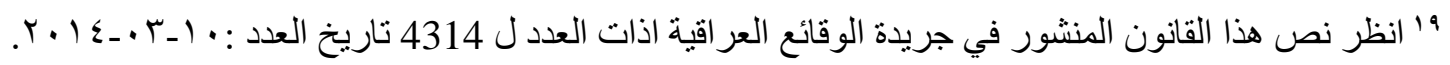

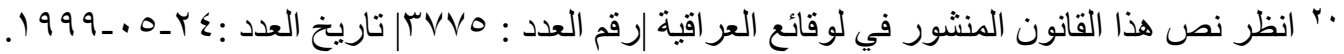
بr انظر نص الفقرة اولا من هذا القانون التي قضت - يستحق رجل الثرطة رواتبه كاملة طوال مدة بقائه في المسنشفى اذا كان مرضده ناشئًاً عن الخدمة او من جر ائها بَّ انظر نص الفقرة ثانيا من المادة سTr من هذا القانون التي قضت - يستحق رجل الثرطة رواتبه كاملة طوال مدة

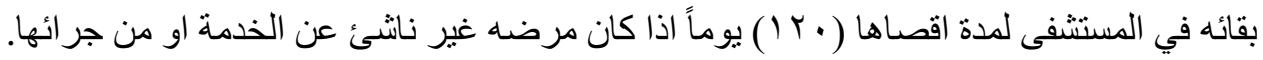

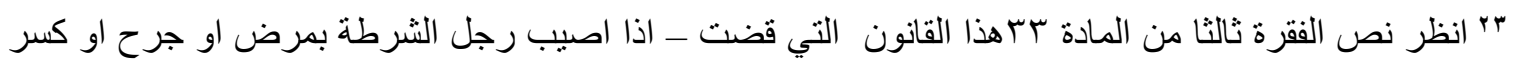
ناشئ عن الخدمة فيجوز منحه اجازة مرضية مدة لاتزيد على ( (1) سنة واحدة بر اتب تام فضلا عن المدة التي يقضيها في المسنتفى. ء انظر نص الفقرة رابعا من المادة بr من هذا القانون التي قضت ـاذا اصيب رجل الثرطة بمرض غير ناثنئ عن

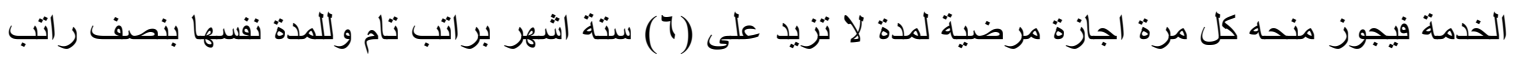
فضلا عن المدة التي يقضيها في المستشفى. هr انظر نص الفقرة خامسا من المادة سب من هذا القانون التي قضت ـتعد اجازة المرضية لرجل الثرطة المصاب بمرض معد او بمرض لا يرجى شفاؤه غير ناثـئ عن الخدمة بر اتب تام لمدة اقصاها ( (1) سنة واحدة فضلا على مدة مكوثه في المستشفى. 


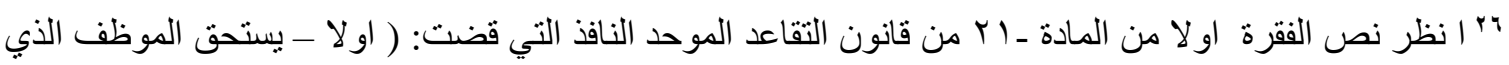
يحال الى التقاعد الر اتب التقاعدي اذا كانت لديه خدمة تقاعدية لا تقل عن( 10 ( ) خمسة عشر سنة و لا يصرف الر اتب التقاعدي الا اذا كان قد اكمل ( •• ) خمسون سنة من عمره وفي كل الاحوال لا يصرف عن الفترة السابقة لتاريخ اكماله السن الدذكورة باستثناء حالات الوفاة والاستشهاد والاحالة الى التقاعد لأسباب صحية والمحالين الى التقاعد وفقا لاحكام البند (ثانيا) من المادة (l' (1) من هذا القانون) .

${ }^{27}$ Hawkins, B. Denise ,30 Years Later: AIDS Experts Reflect on Efforts to Eradicate the Disease, Create Awareness about How It Is Transmitted, PUBLICATION: Diverse Issues in Higher Education, VOLUME/ISSUE: Vol. 28, No. 15,PUBLICATION DATE: September 1, 2011.

28 Adina Nack Damaged Goods? Women Living with Incurable Sexually Transmitted Diseases, PUBLISHER:Temple University Press PLACE OF PUBLICATION:Philadelphia PUBLICATION YEAR:2008.

${ }^{29}$ Kerr T, Kimber J, Debeck K, Wood E (2007). "The role of safer injection facilities in the response to HIV/AIDS among injection drug users". Curr HIV/AIDS Rep. 4 (4): 15864doi:10.1007/s11904-007-0023-8. PMID 18366946

Wodak A, Cooney A (2006). "Do needle syringe programs reduce HIV infection among injecting drug users: a comprehensive review of the international evidence". Subst Use Misuse. 41 (6-7): 777-813. doi:10.1080/10826080600669579. PMID 16809167.

30 Cecilia Van HollenBirth in the Age of AIDS: Women, Reproduction, and HIV/AIDS in India: Stanford University Press, Stanford, CA 2013.

$$
\text { آبا نظر في هذه الاطو ار ودورة حياة الفايروس المسبب لهذا المرض المقالة المعنونة }
$$

The HIV Life Cycle (Last updated 9/13/2016; last reviewed 9/8/2016)

https://aidsinfo.nih.gov/education-materials/fact-sheets/19/73/the-hiv-life-cycle.

19-Luft BJ, Chua A (2000). "Central Nervous

${ }^{32}$ System Toxoplasmosis in HIV Pathogenesis, Diagnosis, and Therapy". Curr. Infect. Dis. Rep. 2 (4): 358-362. doi:10.1007/s11908-000-0016-X. PMID 11095878. rant I, Sacktor H, McArthur J (2005). "HIV neurocognitive disorders" (PDF). In H. E. Gendelman, I. Grant, I. Everall, S. A. Lipton, and S. Swindells. (ed.). The Neurology 
مجلة العلوم القانونية/ كلية القانون - جامعة بغداد / العدد الخاص لبحوث مؤتمر فرع القانون العام المنعقد تحت عنوان"الاصلاح

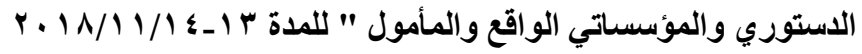

of AIDS(PDF) ( الطبعة الطحات rVT. ISBN 0-19-852610-5.

rَّ انظر جدو لا مفصلا بهذه الامر اض ملحقا بتعليمات الخاصة بالاجازة الخاصة بالمرض الذي بستوجب مدة طويلة للعلاج و الامر اض الخبيثة و المستعصية ذات الرقم ع ا لسنة ... . النافذة و المنشورة في جريدة الوقائع العر اقية ذات

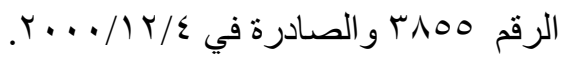


المصادر

\section{References}

\begin{tabular}{|c|c|}
\hline \multicolumn{2}{|l|}{ •المراجع العربية Arabic References $\quad$ • } \\
\hline 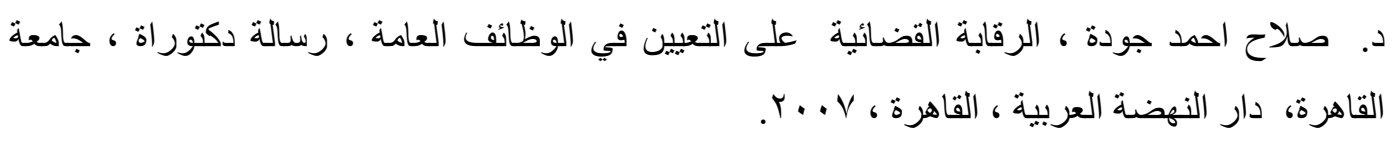 &. $\mathbf{I}$ \\
\hline د. عبدالحميد القضاة ,العوز المناعي المكتسب حصاد الثذوذ ، دار ابن قدامى للطباعة، القاهرة 719 امه، & .II \\
\hline دالقاهرة ، ـحمد إبر اهيم علي ، مبدأ المساو اة في تقلد الوظائف العامة ـ دراسة مقارنة، رسالة دكتور اة ، جامعة & .III \\
\hline 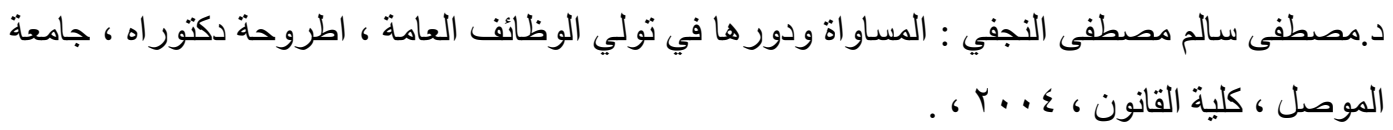 & .IV \\
\hline
\end{tabular}

\section{• المراجع الاجنبية Foreign References.}

I. Hawkins, B. Denise ,30 Years Later: AIDS Experts Reflect on Efforts to Eradicate the Disease, Create Awareness about How It Is Transmitted, PUBLICATION: Diverse Issues in Higher Education, VOLUME/ISSUE: Vol. 28, No. 15,PUBLICATION DATE: September 1, 2011.

II. Kerr T, Kimber J, Debeck K, Wood E (2007). "The role of safer injection facilities in the response to HIV/AIDS among injection drug users". Curr HIV/AIDS Rep. 4 (4): 158-64doi:10.1007/s11904-007-0023-8. PMID 18366946

III. Adina Nack Damaged Goods? Women Living with Incurable Sexually Transmitted Diseases, PUBLISHER:Temple University Press PLACE OF PUBLICATION:Philadelphia PUBLICATION YEAR:2008.

IV. Cecilia Van HollenBirth in the Age of AIDS: Women, Reproduction, and HIV/AIDS in India: Stanford University Press, Stanford, CA 2013.

V. Luft BJ, Chua A (2000). "Central Nervous (System Toxoplasmosis in HIV Pathogenesis, Diagnosis, and Therapy". Curr. Infect. Dis. Rep. 2 (4): 358362. doi:10.1007/s11908-000-0016-x. PMID 11095878. rant I, Sacktor H, 
McArthur J (2005). "HIV neurocognitive disorders" (PDF). In H. E. Gendelman, I. Grant, I. Everall, S. A. Lipton, and S. Swindells. (ed.). The Neurology of AIDS(PDF) ( $($ nd). London, UK: Oxford University Press. ISBN 0-19-852610-5.

VI. The HIV Life Cycle (Last updated 9/13/2016; last reviewed 9/8/2016) https://aidsinfo.nih.gov/education-materials/fact-sheets/19/73/the-hiv-life-cycle.

VII. Wodak A, Cooney A (2006). "Do needle syringe programs reduce HIV infection among injecting drug users: a comprehensive review of the international evidence". Subst Use Misuse. 41 (6-7): 777813. doi:10.1080/10826080600669579. PMID 16809167. 